\title{
Synthesis and biological evaluation of novel 2,3- dihydro-1H-1,5-benzodiazepin-2-ones; potential imaging agents of the metabotropic glutamate 2 receptor†
}

Cite this: Med. Chem. Commun., 2013, 4, 1118

\author{
Lynne Gilfillan, ${ }^{\text {a }}$ Adele Blair, ${ }^{\text {a }}$ Brian J. Morris, ${ }^{\text {b }}$ Judith A. Pratt, ${ }^{c}$ Lutz Schweiger, $^{d}$ \\ Sally Pimlott ${ }^{\mathrm{e}}$ and Andrew Sutherland ${ }^{* a}$
}

Received 16th April 2013

Accepted 23rd May 2013

DOI: 10.1039/c3md00110e

www.rsc.org/medchemcomm

A focused library of novel 2,3-dihydro- $1 \mathrm{H}$-1,5-benzodiazepin-2-ones containing sites for ${ }^{11} \mathrm{C}$-, ${ }^{18} \mathrm{~F}$ - and ${ }^{123} \mathrm{I}$ labelling have been prepared and evaluated against membrane expressing human recombinant metabotropic glutamate 2 receptor (mGluR2). The compounds were found to be non-competitive antagonists with nanomolar affinity. HPLC evaluation of the physiochemical properties of these compounds identified two candidates for PET and SPECT imaging of mGluR2.

\section{Introduction}

Metabotropic glutamate receptors (mGluR) are a superfamily of G-protein coupled receptors found embedded within cell membranes. In the central nervous system (CNS), they modulate -glutamate neurotransmission and are also considered to affect dopaminergic and adrenergic neurotransmission. ${ }^{1}$ Eight members of the family of mGluRs (1-8) have been cloned and are separated into three groups based on their signal induction pathway and sequence homology. ${ }^{2}$ Group 1 receptors (mGluR1 and 5) are positively coupled to the activity of phospholipase C, whereas group II (mGluR2 and 3) and group III (mGluR4 and 6-8) receptors which have a different pharmacology, are both negatively coupled to the activity of adenyl cyclase. ${ }^{3}$

The development of pharmacological agents targeting the mGluRs has been recognised as a possible approach for the treatment of various CNS disorders such as depression, anxiety and schizophrenia. ${ }^{4}$ More specifically, mGluR2/3 agonists have been shown to exhibit anxiolytic and antipsychotic properties

${ }^{a}$ WestCHEM, School of Chemistry, The Joseph Black Building, University of Glasgow, Glasgow, G12 8QQ, UK. E-mail: Andrew.Sutherland@glasgow.ac.uk; Fax: +44 (0) 141330 4888; Tel: +44 (0)141330 5936

${ }^{b}$ Institute of Neuroscience and Psychology, University of Glasgow, Glasgow, G12 8QQ, $U K$

${ }^{c}$ Centre for Neuroscience, Strathclyde Institute of Pharmacy and Biomedical Sciences, University of Strathclyde, Glasgow, G4 ORE, UK

'John Mallard Scottish PET Centre, School of Medicine and Dentistry, University of Aberdeen, Foresterhill, Aberdeen, AB25 2ZD, UK

${ }^{e}$ West of Scotland Radionuclide Dispensary, University of Glasgow and North Glasgow University Hospital NHS Trust, Glasgow, G11 6NT, UK

$\dagger$ Electronic supplementary information (ESI) available: Experimental procedures, spectroscopic data for all compounds synthesised, details of biological evaluation and HPLC methods, as well as NMR spectra for all new compounds. See DOI: 10.1039/c3md00110e while mGluR2/3 antagonists may be useful as anti-depressants and cognitive enhancers. ${ }^{4 b, 5,6}$ Recently, Woltering and co-workers initiated a programme of research to find new mGluR2/3 ligands with increased receptor selectivity and improved physiochemical properties. ${ }^{7}$ Through a random screening programme, a library of compounds based on a 2,3-dihydro- $1 \mathrm{H}$-1,5-benzodiazepin-2one core 1 (Fig. 1) were identified that showed excellent affinity as non-competitive antagonists when tested against rat mGluR2 receptors. The most potent series of compounds contained 5- and<smiles>[R][R14]1ccc2c(c1)N=C(c1cccc([R3])c1)CC(=O)N2</smiles>

Fig. 1 2,3-Dihydro-1H-1,5-benzodiazepin-2-one derivatives. 
6-membered heterocyclic motifs such as 1-imidazoles, 1,2,3-triazoles and 4-pyridines at the $3^{\prime}$-position $\left(\mathrm{R}_{3}\right)$.

We have a longstanding interest in developing molecular tracers for positron emission tomography (PET) and single photon emission computed tomography (SPECT) imaging of neurological receptor targets. ${ }^{8}$ Based on the $3^{\prime}$-imidazole derived 2,3-dihydro- $1 \mathrm{H}$-1,5-benzodiazepin-2-ones identified by the Woltering group, we proposed to discover novel candidates that could be used for PET and SPECT imaging of mGluR2 in schizophrenia. Such compounds would have the potential to be used for the diagnosis of schizophrenia as well as in the evaluation of new drugs and in the measurement of treatment response.

Herein, we report our studies on the design and synthesis of novel 3 '-imidazole derived 2,3-dihydro- $1 H$-1,5-benzodiazepin-2ones bearing an iodophenyl moiety $(2,3)$ for SPECT imaging or methyl and fluoro groups $(\mathbf{4}, \mathbf{5})$ for PET imaging as well as a compound with multiple labelling sites (6) which could be used for either modality (Fig. 1). We also report the biological assessment of these compounds against membrane expressing human recombinant mGluR2 as well as their suitability as neurological imaging agents by the evaluation of their physiochemical properties.

\section{Results and discussion}

We began our studies with the synthesis of 3- and 4-iodophenyl derivatives for application in SPECT imaging. Our general strategy involved the preparation of selectively protected 1,2diaminobenzenes which could be coupled and cyclised with a $\beta$-keto ester to generate the 2,3-dihydro- $1 \mathrm{H}$-1,5-benzodiazepin2-one core. Iodination would then be incorporated at the last stage allowing this step to be modified for eventual radioiodination. As such, 2-nitroaniline (7) was iodinated regioselectively using iodine monochloride ${ }^{9}$ and this was converted to Boc-protected derivative 9 using a two-step strategy involving diprotection, ${ }^{10}$ followed by selective removal of one of the Bocprotecting groups (Scheme 1). This approach was found to be more efficient for all 1,2-diaminobenzenes prepared during this study rather than direct mono-Boc protection of the aniline. A palladium(0)-mediated Suzuki-Miyaura reaction under standard conditions with 3- or 4-bromophenylboronic acid and

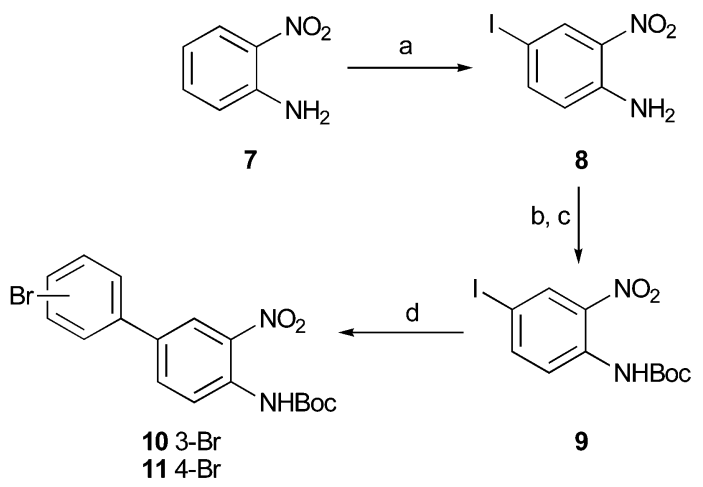

Scheme 1 Reagents and conditions: (a) ICl, $\mathrm{NaOAc}, \mathrm{AcOH}, 90{ }^{\circ} \mathrm{C}, 88 \%$; (b) $\mathrm{Boc}_{2} \mathrm{O}$ (2.2 eq.), $\mathrm{Et}_{3} \mathrm{~N}$, DMAP (0.2 eq.), $\mathrm{CH}_{2} \mathrm{Cl}_{2}, 70 \%$; (c) TFA, $\mathrm{CH}_{2} \mathrm{Cl}_{2}, 98 \%$; (d) 3- or 4-I$\mathrm{PhB}(\mathrm{OH})_{2},\left(\mathrm{Ph}_{3} \mathrm{P}\right)_{4} \mathrm{Pd}(2 \mathrm{~mol} \%), \mathrm{K}_{2} \mathrm{CO}_{3}, \mathrm{DMF}-\mathrm{H}_{2} \mathrm{O}, 10$ (72\%), 11 (78\%).

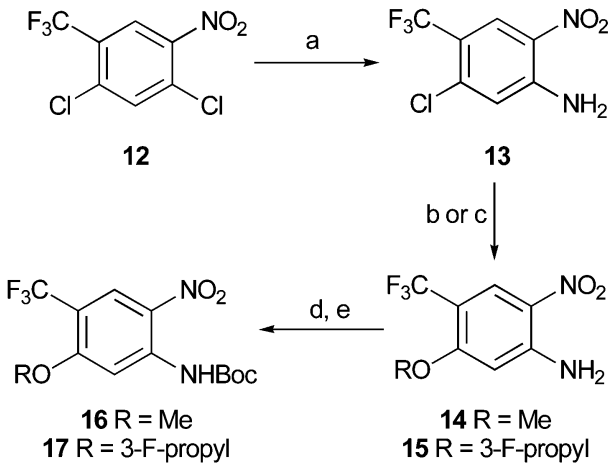

Scheme 2 Reagents and conditions: (a) $\mathrm{NH}_{3}$, 1,4-dioxane, $100{ }^{\circ} \mathrm{C}, 76 \%$; (b) $\mathrm{MeOH}, \mathrm{KOH}, \mathrm{DMSO}, 60{ }^{\circ} \mathrm{C}, 97 \%$; (c) 3-fluoropropan-1-ol, $\mathrm{K}_{2} \mathrm{CO}_{3}, \mathrm{DMSO}, 120^{\circ} \mathrm{C}$, $71 \%$; (d) $\mathrm{Boc}_{2} \mathrm{O}$ (2.2 eq.), $\mathrm{Et}_{3} \mathrm{~N}$, DMAP (0.2 eq.), $\mathrm{CH}_{2} \mathrm{Cl}_{2}, 95 \%(\mathrm{R}=\mathrm{Me}), 82 \%(\mathrm{R}=3-$ F-propyl); (e) TFA, $\mathrm{CH}_{2} \mathrm{Cl}_{2}, 16$ (100\%), 17 (98\%).

using potassium carbonate as the base gave the corresponding bi-phenyl derivatives $\mathbf{1 0}$ and $\mathbf{1 1}$ in good overall yields.

The aromatic core for the generation of the potential PET tracers was prepared as shown in Scheme 2. 1,5-Dichloro-2nitro-4-(trifluoromethyl)benzene (12) was selectively aminated with ammonia to give $\mathbf{1 3}$ in good yield.11 Introduction of the potential PET labels by nucleophilic aromatic substitution of $\mathbf{1 3}$ with either methanol or 3-fluoropropan-1-ol gave alkoxy derivatives 14 and 15. Application of the two-step approach for Bocprotection of the anilines then gave compounds $\mathbf{1 6}$ and $\mathbf{1 7 .}$

The final compound prepared in this series required both an iodophenyl group and methoxy moiety for application in either SPECT or PET imaging, respectively. The 1,2-diaminobenzene core was initially prepared from 2-nitro-5-chloroaniline (18) which was subjected to a regioselective iodination with iodine monochloride (Scheme 3). Nucleophilic aromatic substitution at the 5-position with methanol allowed introduction of the methoxy group in excellent yield. The two-step Boc-protection sequence was then employed to give 21 and this was followed by a Suzuki-Miyaura reaction with 4-bromophenylboronic acid to give functionalised biphenyl 22 in good yield over the five steps.

The final stage of the synthesis of the selectively protected 1,2diaminobenzenes required the reduction of the 2-nitro group. As several of these compounds $(\mathbf{1 0}, \mathbf{1 1}$ and 22) contained labile

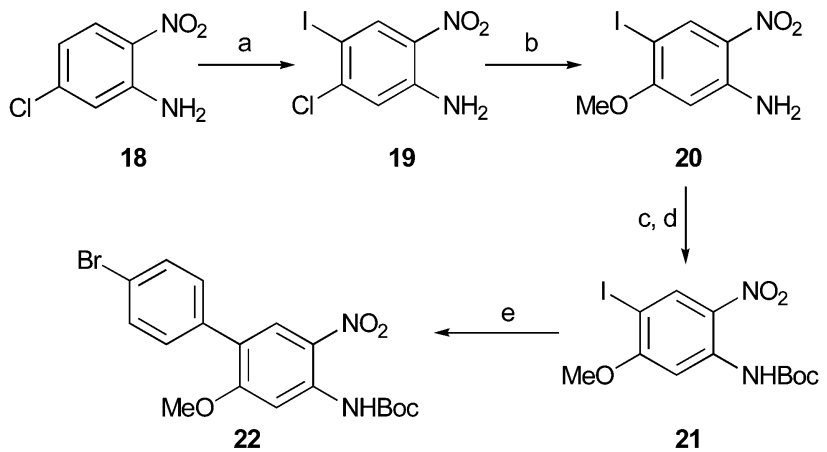

Scheme 3 Reagents and conditions: (a) ICl, NaOAc, $\mathrm{AcOH}, 80{ }^{\circ} \mathrm{C}, 92 \%$; (b) $\mathrm{MeOH}, \mathrm{KOH}, \mathrm{DMSO}, 60{ }^{\circ} \mathrm{C}, 94 \%$; (c) Boc $2 \mathrm{O}$ (2.2 eq.), Et ${ }_{3} \mathrm{~N}$, DMAP (0.2 eq.), $\mathrm{CH}_{2} \mathrm{Cl}_{2}$, $96 \%$; (d) TFA, $\mathrm{CH}_{2} \mathrm{Cl}_{2}, 100 \%$; (e) 4-I-PhB(OH) $2,\left(\mathrm{Ph}_{3} \mathrm{P}\right)_{4} \mathrm{Pd}(2 \mathrm{~mol} \%), \mathrm{K}_{2} \mathrm{CO}_{3}, \mathrm{DMF}-$ $\mathrm{H}_{2} \mathrm{O}, 66 \%$. 
<smiles>[R2]c1cc(NC([R])(C)O[Na])c([N+](=O)[O-])cc1[R]</smiles>

$9,10,11$,

$16,17,22$<smiles>[R]c1cc(N)c(NC(=O)OC(C)(C)C)cc1[R2]</smiles>

$23 \mathrm{R}_{1}=\mathrm{I}, \mathrm{R}_{2}=\mathrm{H}$

$24 \mathrm{R}_{1}=3-\mathrm{Br}-\mathrm{Ph}, \mathrm{R}_{2}=\mathrm{H}$

$25 \mathrm{R}_{1}=4-\mathrm{Br}-\mathrm{Ph}, \mathrm{R}_{2}=\mathrm{H}$

$26 \mathrm{R}_{1}=\mathrm{CF}_{3}, \mathrm{R}_{2}=\mathrm{OMe}$

$27 \mathrm{R}_{1}=\mathrm{CF}_{3}, \mathrm{R}_{2}=3$-F-propyl

$28 \mathrm{R}_{1}=4-\mathrm{Br}-\mathrm{Ph}, \mathrm{R}_{2}=\mathrm{OMe}$

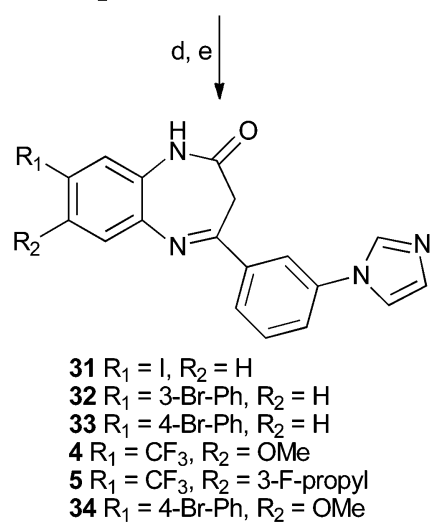

Scheme 4 Reagents and conditions: (a) $\mathrm{SnCl}_{2} \cdot 2 \mathrm{H}_{2} \mathrm{O}$, EtOAc/pyridine, 23 (91\%), 24 (72\%), 25 (63\%), 26 (85\%), 27 (83\%), 28 (75\%); (b) 40\% glyoxyl, MeOH then $\mathrm{NH}_{4} \mathrm{Cl}, \mathrm{CH}_{2} \mathrm{O}, \mathrm{H}_{3} \mathrm{PO}_{4}, 58 \%$; (c) t-BuOAc, LiHMDS, THF, $80 \%$; (d) $\Delta$, toluene; (e) TFA, $\mathrm{CH}_{2} \mathrm{Cl}_{2}$, yields over two steps: $\mathbf{3 1}$ (39\%), $\mathbf{3 2}$ (55\%), $\mathbf{3 3}$ (66\%), $\mathbf{4}(48 \%), \mathbf{5}(72 \%), \mathbf{3 4}$ (69\%).

carbon-bromine bonds, a mild procedure was required. Initial attempts using transfer hydrogenation with ammonium formate led to reduction of both the bromide and nitro groups. However, a successful transformation was identified using tin(II) chloride dihydrate which led to the reduction of 9-11, 16, 17 and 22 under basic conditions in generally high yields (Scheme 4 )..$^{12}$ The $\beta$-keto ester fragment 30 required for coupling with the 1,2-diaminobenzenes to generate the 2,3-dihydro- $1 H$-1,5-benzodiazepin-2-ones was prepared using a two stage approach. Methyl $3-\left(1^{\prime} H\right.$-imidazol-1'-yl)benzoate was initially synthesised from methyl 3-aminobenzoate (29) using an imidazole ring synthesis described by Zhang and co-workers. ${ }^{13}$ Claisen condensation with tert-butyl acetate gave 30 in $80 \%$ yield. ${ }^{14}$ Coupling of 30 with the 1,2-diaminobenzenes was performed under reflux to give the corresponding $\beta$-ketoamides. ${ }^{7}$ Subsequent treatment with TFA to remove the Boc-protecting group and facilitate cyclisation led to the isolation of the 2,3-dihydro- $1 H$-1,5-benzodiazepin-2-ones in good yields over the two steps.

The final stage of the synthesis of the SPECT compounds involved the iodination of the bromophenyl groups. Initial attempts using a direct copper catalysed halogen exchange reaction resulted in only isomerisation of the cyclic imine to the corresponding enamine. ${ }^{15}$ Instead, a palladium(0)-mediated stannylation of the bromides with hexamethylditin was followed by an oxidative iododestannylation and this gave the target iodides, 2, 3 and $\mathbf{6}$ cleanly, in good yields over the two steps (Scheme 5).

With the series of 2,3-dihydro-1 $\mathrm{H}$-1,5-benzodiazepin-2-ones in hand, a functional $\left[{ }^{35} \mathrm{~S}\right] \mathrm{GTP} \gamma \mathrm{S}$ assay using membrane expressing human mGluR2 was optimised. ${ }^{16}$ The $\left[{ }^{35} \mathrm{~S}\right] \mathrm{GTP} \gamma \mathrm{S}$ assay is commonly used to determine binding to G-protein coupled receptors in vitro. On stimulation of the receptor, in this case mGluR2, with an agonist such as L-glutamate, $\left[{ }^{35} \mathrm{~S}\right]$ guanosine $5^{\prime}$ - $\left(\gamma\right.$-thio)triphosphate $\left(\left[{ }^{35} \mathrm{~S}\right] \mathrm{GTP} \gamma \mathrm{S}\right)$ binds irreversibly to the $\mathrm{G} \alpha$ subunit of the G-protein. This accumulation of $\left[{ }^{35} \mathrm{~S}\right] \mathrm{GTP} \gamma \mathrm{S}$ can be quantified by liquid scintillation analysis. Addition of a non-competitive antagonist disrupts binding of the agonist and thus, lowers accumulation of the $\left[{ }^{35} \mathrm{~S}\right] \mathrm{GTP} \gamma \mathrm{S}$.

Before biological testing of the 2,3-dihydro- $1 \mathrm{H}$-1,5-benzodiazepin-2-ones, control experiments were performed to

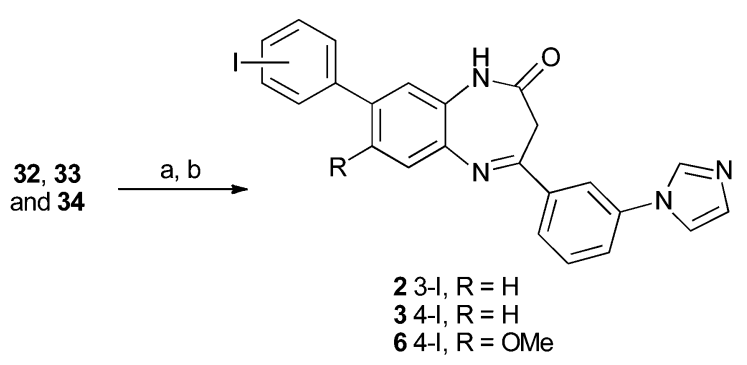

Scheme 5 Reagents and conditions: (a) $\left(\mathrm{Me}_{3} \mathrm{Sn}\right)_{2},\left(\mathrm{Ph}_{3} \mathrm{P}\right)_{4} \mathrm{Pd}(10 \mathrm{~mol} \%), 1,4-$ dioxane, $90{ }^{\circ} \mathrm{C}$; (b) Nal, chloramine-T, EtOH, 2 (69\%), 3 (42\%), 6 (47\%).
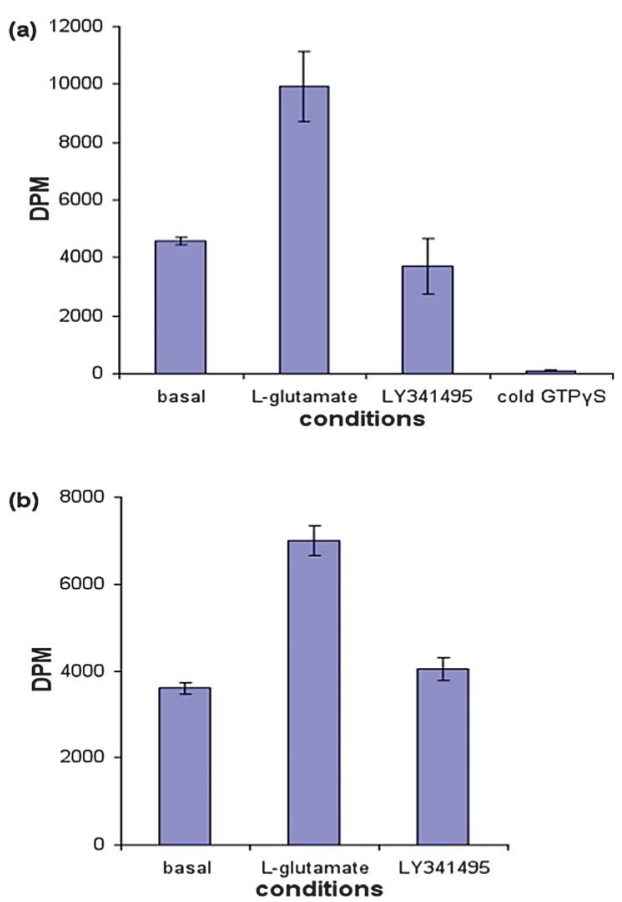

Fig. 2 Graphs of control experiments with membrane expressing human mGluR2, at: (a) $100 \mu \mathrm{M}$ L-glutamate and (b) $10 \mu \mathrm{M}$ L-glutamate (DPM = disintegrations per minute). 
optimise the assay. Initially, addition of $\left[{ }^{35} \mathrm{~S}\right] \mathrm{GTP} \gamma \mathrm{S}$ and guanosine diphosphate to the membrane showed the expected basal binding (Fig. 2a). Stimulation with $100 \mu \mathrm{M}$ L-glutamate resulted in a $117 \%$ increase over basal binding. Next, addition of the known competitive antagonist LY341495 (10 $\mu \mathrm{M})$ showed the expected reduction of binding back to basal level. ${ }^{17}$ To gauge the level of non-specific binding of $\left[{ }^{35} \mathrm{~S}\right] \mathrm{GTP} \gamma \mathrm{S}$, the assay was repeated with the addition of $10 \mu \mathrm{M}\left[{ }^{32} \mathrm{~S}\right] \mathrm{GTP} \gamma \mathrm{S}$. This confirmed the high specificity of $\left[{ }^{35} \mathrm{~S}\right] \mathrm{GTP} \gamma \mathrm{S}$ for the G-protein. Finally, a further series of experiments using only $10 \mu \mathrm{M}$ L-glutamate showed a similar level of stimulation (95\%) and therefore, this

Table 1 Inhibition of membrane expressing human recombinant mGluR2 by 2,3-dihydro-1H-1,5-benzodiazepin-2-ones

$\overline{\text { Compound }} \quad \mathrm{IC}_{50}{ }^{a}(\mathrm{nM})$
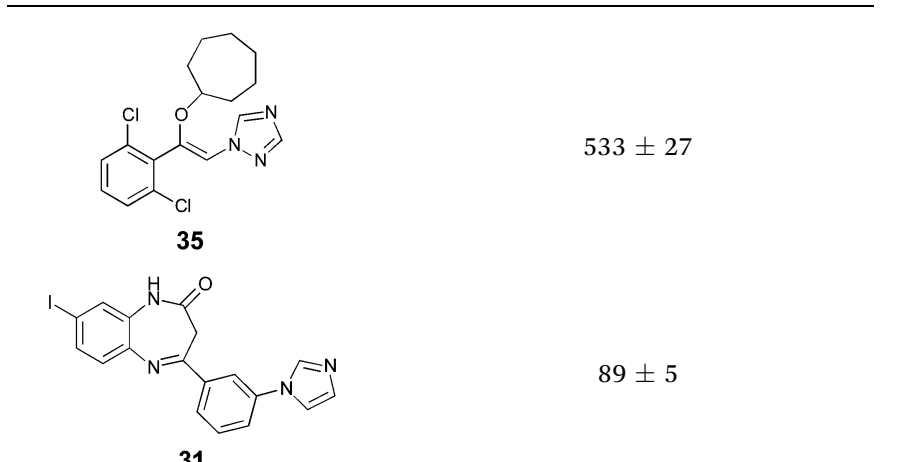

$89 \pm 5$

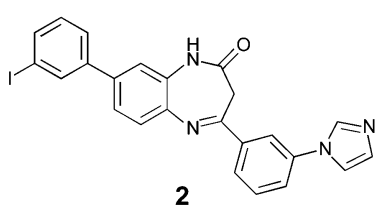

$132 \pm 7$

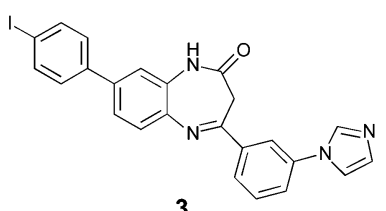

$133 \pm 24$

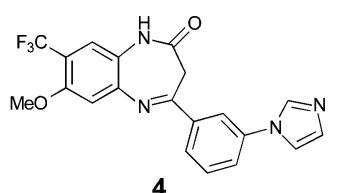

$91 \pm 30$

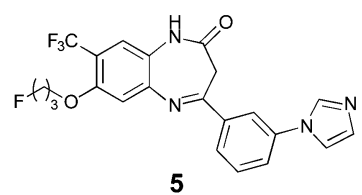

$100 \pm 14$

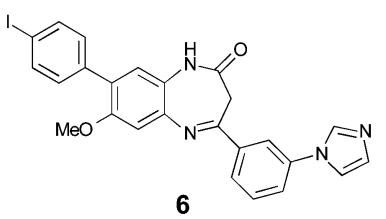

$89 \pm 46$

\footnotetext{
${ }^{a} \mathrm{IC}_{50}$ values are the mean $\pm \mathrm{SD}$ of three independent experiments except for compounds 3 and $\mathbf{6}$, where $n=2 .{ }^{19}$
}

Table 2 Physiochemical values

\begin{tabular}{lrrrr}
\hline Compound & $\log P^{a}$ & \multicolumn{1}{c}{$P_{\mathrm{m}}{ }^{b}$} & \multicolumn{1}{c}{$K_{\mathrm{m}}{ }^{b}$} & $\% \mathrm{PPB}^{c}$ \\
\hline 31 & 4.60 & 0.51 & 218.40 & 94.92 \\
$\mathbf{2}$ & 5.73 & $>2.27$ & $>1144.81$ & 98.46 \\
$\mathbf{3}$ & 5.77 & $>2.27$ & $>1144.81$ & 98.67 \\
$\mathbf{4}$ & 4.67 & 0.44 & 176.15 & 92.41 \\
$\mathbf{5}$ & 5.06 & 0.77 & 343.73 & 95.12 \\
$\mathbf{6}$ & 5.72 & $>2.13$ & $>1138.17$ & 98.32
\end{tabular}

${ }^{a}$ Determined using $\mathrm{C}_{18}$ column. ${ }^{b}$ Determined using immobilised artificial membrane (IAM) column. ${ }^{c}$ Determined using human serum albumin (HSA) coated column.

concentration was used during the biological evaluation of the 2,3-dihydro- $1 H$-1,5-benzodiazepin-2-ones (Fig. 2b).

As a standard, commercially available Ro 64-5229 35, a known selective non-competitive mGluR2 antagonist was initially tested using the assay described above. This produced an $\mathrm{IC}_{50}$ value $(533 \mathrm{nM}$ ) of similar magnitude to that previously reported for 35 when tested against rat mGluR2 transfected cell membranes (Table 1). ${ }^{18}$ The series of 2,3-dihydro- $1 H$-1,5-benzodiazepin-2-ones were then evaluated. As can be observed for Table 1, all of the compounds showed excellent affinity for mGluR2 with $\mathrm{IC}_{50}$ values ranging from 89 to $133 \mathrm{nM}$. In particular, the sterically less-encumbered compounds $\mathbf{3 1}$ and 4 showed six times more potency than the standard, noncompetitive antagonist, Ro 64-5229 35. ${ }^{19}$

Selecting potential candidates as neurological imaging agents for further development requires determination of a range of physiochemical properties. For the compound to transverse brain capillary endothelial cells and penetrate the blood brain barrier, permeability across the plasma membrane is important. Furthermore, for compounds which mainly transport across cell membranes through passive diffusion, determining the membrane partition coefficient is crucial for successful development. Based on a recently reported study of HPLC methods for determining these key physiochemical properties of imaging agents, ${ }^{20}$ the partition coefficient $(\log P)$, permeability $\left(P_{\mathrm{m}}\right)$, the membrane partition coefficient $\left(K_{\mathrm{m}}\right)$ and the percentage of plasma protein binding (\%PPB) of all six 2,3-dihydro- $1 H-1,5-$ benzodiazepin-2-ones were assessed (Table 2). The previously reported study performed by Tavares et al., of ten successful imaging agents established the limits of each of these parameters $\left(\log P<4, P_{\mathrm{m}}<0.5, K_{\mathrm{m}}<250, \%\right.$ PPB $\left.<95 \%\right)$. Based on these criteria, compounds 31 and 4 were found to have the best physiochemical properties for further development. While the $\log P$ values were just above the acceptable limit, Tavares et al., do emphasise that $\log P$ is the weakest predictor of brain penetration. More importantly, $\mathbf{3 1}$ and $\mathbf{4}$ gave excellent results for permeability, membrane partition coefficient and percentage of plasma protein binding. Based on these results, $\mathbf{3 1}$ and $\mathbf{4}$ have been selected for further development as molecular imaging agents for mGluR2.

Having established 2,3-dihydro- $1 \mathrm{H}$-1,5-benzodiazepin-2-ones 31 and 4 as potential imaging agents for mGluR2, it was important to identify synthetic approaches for the radiolabelling of these compounds. Radioiodination of compound 31 for SPECT 
imaging could be envisaged using the standard two-step stannylation/oxidative iodo-destannylation already utilised for the synthesis of compounds 2, 3 and 6 (Scheme 5). Thus, application of this approach with 31 as the precursor and using $\left[{ }^{123} \mathrm{I}\right]$ - or $\left[{ }^{125} \mathrm{I}\right]$-sodium iodide would allow introduction of radioiodine at the final step. While there are toxicity issues in using organotin compounds for the preparation of neurological SPECT imaging agents, the radioiodinated products are generally purified to a high level using HPLC.

The synthesis described for the preparation of compound 4 (Schemes 2 and 4) where the methyl group is introduced at an early stage would not be amenable to $\left[{ }^{11} \mathrm{C}\right]$-labelling of this compound. Therefore, a synthetic route was developed to a suitable precursor that would allow $\left[{ }^{11} \mathrm{C}\right]$-methylation as the final step (Scheme 6). Previously synthesised chloroaniline 13 was subjected to a nucleophilic aromatic substitution reaction with benzyl alcohol which gave 36 in $60 \%$ yield. Boc-protection of 36 using the two-step approach followed by reduction of the nitrogroup with tin(II) chloride dihydrate gave selectively protected 1,2diaminobenzene 38 in excellent overall yield. Coupling of 38 with $\beta$-keto ester 30 and TFA mediated cyclisation gave 2,3-dihydro$1 H$-1,5-benzodiazepin-2-one 39 in $65 \%$ yield over the two steps. Finally, removal of the benzyl protecting group using boron tribromide gave phenol $\mathbf{4 0}$ in $\mathbf{8 1 \%}$ yield. This seven-step approach

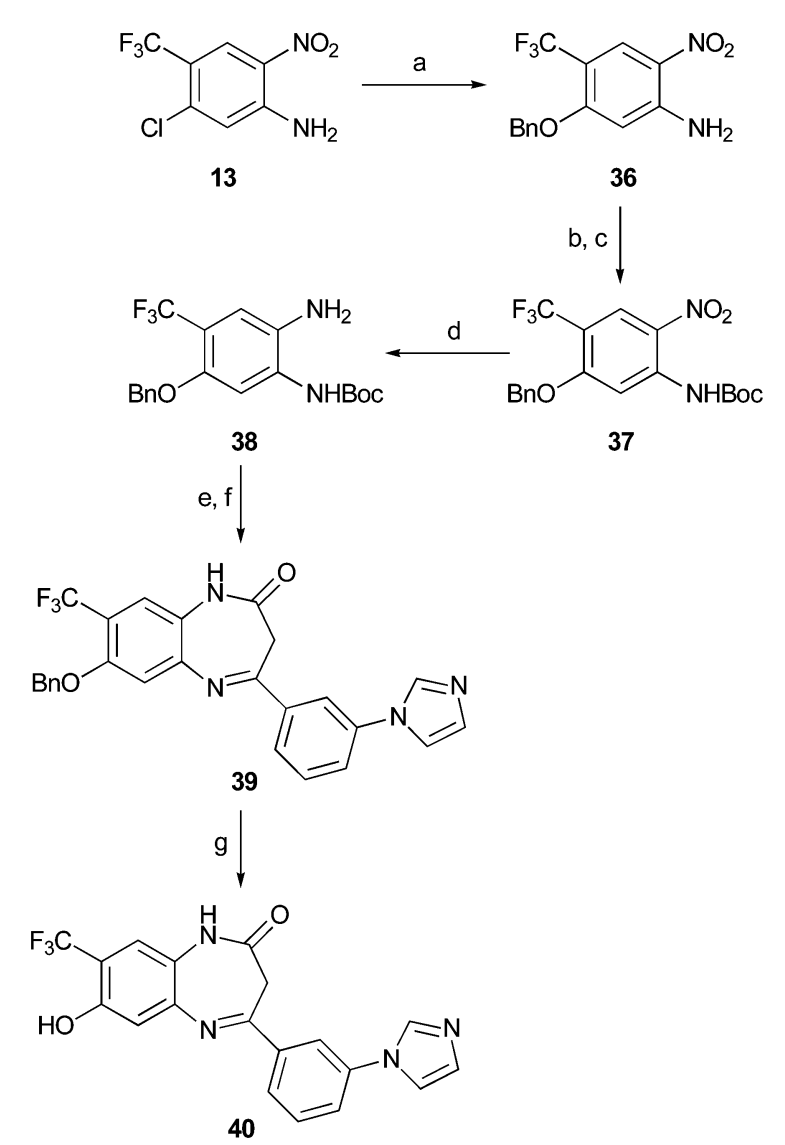

Scheme 6 Reagents and conditions: (a) $\mathrm{BnOH}, \mathrm{KOH}, n-\mathrm{Bu}_{4} \mathrm{NBr}, 60{ }^{\circ} \mathrm{C}, 60 \%$; (b) $\mathrm{Boc}_{2} \mathrm{O}$ (2.2 eq.), $\mathrm{Et}_{3} \mathrm{~N}$, DMAP (0.2 eq.), $\mathrm{CH}_{2} \mathrm{Cl}_{2}, 98 \%$; (c) $\mathrm{TFA}, \mathrm{CH}_{2} \mathrm{Cl}_{2}, 97 \%$; (d) $\mathrm{SnCl}_{2} \cdot 2 \mathrm{H}_{2} \mathrm{O}, \mathrm{EtOH}, 70{ }^{\circ} \mathrm{C}, 98 \%$; (e) 30, $\Delta$, toluene; (f) TFA, $\mathrm{CH}_{2} \mathrm{Cl}_{2}, 65 \%$ yields over two steps; (g) $\mathrm{BBr}_{3}, \mathrm{CH}_{2} \mathrm{Cl}_{2}, 81 \%$. allows rapid access to a precursor which on alkylation with $\left[{ }^{11} \mathrm{C}\right]-$ methyl iodide would give the radiolabelled version of compound 4 for PET imaging. Alkylation with other groups would also result in the late-stage preparation of further non-labelled analogues in this series for biological testing.

\section{Conclusions}

In summary, six novel 2,3-dihydro- $1 H$-1,5-benzodiazepin-2-ones bearing sites for radiolabelling have been successfully prepared using a two-stage convergent approach involving the coupling and cyclisation of a range of 1,2-diaminobenzenes with an imidazole derived $\beta$-keto ester. Biological evaluation of these compounds against membrane expressing human mGluR2 using a functional $\left[{ }^{35} \mathrm{~S}\right] \mathrm{GTP} \gamma \mathrm{S}$ assay showed these compounds to have excellent affinity as non-competitive antagonists for mGluR2. Evaluation of the key physiochemical properties required for a successful neurological imaging agent using established HPLC methods identified compounds $\mathbf{3 1}$ and 4 as potential SPECT and PET tracers for mGluR2, respectively. Work is currently underway to establish a radiosynthesis of these compounds from precursors $\mathbf{3 1}$ and $\mathbf{4 0}$ and evaluate their mGluR selectivity and biodistribution in vivo.

\section{Acknowledgements}

The authors gratefully acknowledge financial support from SINAPSE (studentship to LG), the Scottish Funding Council (studentship to $\mathrm{AB}$ ) and the University of Glasgow.

\section{Notes and references}

1 J.-Q. Wang and A.-L. Brownell, Curr. Med. Imaging Rev., 2007, 3, 186-205.

2 (a) F. Gasparini and W. Spooren, Curr. Neuropharmacol., 2007, 5, 187-194; (b) R. E. Oswald, A. Ahmed, M. K. Fenwick and A. P. Loh, Curr. Drug Targets, 2007, 8, 573-582.

3 R. Pellicciari, G. Costantino, M. Marinozzi, A. Macchiarulo, E. Camaioni and B. Natalini, Farmaco, 2001, 56, 91-94.

4 (a) M. Récasens, J. Guiramand, R. Aimar, A. Abdulkarim and G. Barbanel, Curr. Drug Targets, 2007, 8, 651-681; (b) C. J. Swanson, M. Bures, M. P. Johnson, A.-M. Linden, J. A. Monn and D. Schoepp, Nat. Rev. Drug Discovery, 2005, 4, 131-144.

5 (a) M. P. Johnson, M. Baez, G. E. Jagdmann, Jr, T. C. Britton, T. H. Large, D. O. Callagaro, J. P. Tizzano, J. A. Monn and D. D. Schoepp, J. Med. Chem., 2003, 46, 3189-3192; (b) S. Spinelli, T. Ballard, S. Gatti-McArthur, G. J. Richards, M. Kapps, T. Woltering, J. Wichmann, H. Stadler, J. Feldon and C. R. Pryce, Psychopharmacology, 2005, 179, 292-302.

6 (a) S. Chaki, R. Yoshikawa, S. Hirota, T. Shimazaki, M. Maeda, N. Kawashima, T. Yoshimizu, A. Yasuhara, K. Sakagami, S. Okuyama, S. Nakanishi and A. Nakazato, Neuropharmacology, 2004, 46, 457-467; (b) G. A. Higgins, T. M. Ballard, J. N. C. Kew, J. G. Richards, J. A. Kemp, G. Adam, T. Woltering, S. Nakanishi and V. Mutel, Neuropharmacology, 2004, 46, 907-917. 
7 (a) T. J. Woltering, G. Adam, A. Alanine, J. Wichmann, F. Knoflach, V. Mutel and S. Gatti, Bioorg. Med. Chem. Lett., 2007, 17, 6811-6815; (b) T. J. Woltering, G. Adam, J. Wichmann, E. Goetschi, J. N. C. Kew, F. Knoflach, V. Mutel and S. Gatti, Bioorg. Med. Chem. Lett., 2008, 18, 1091-1095; (c) T. J. Woltering, J. Wichmann, E. Goetschi, G. Adam, J. N. C. Kew, F. Knoflach, T. M. Ballard, J. Huwyler, V. Mutel and S. Gatti, Bioorg. Med. Chem. Lett., 2008, 18, 2725-2729; (d) T. J. Woltering, J. Wichmann, F. Knoflach, T. M. Ballard, J. Huwyler and S. Gatti, Bioorg. Med. Chem. Lett., 2010, 20, 6969-6974.

8 (a) N. K. Jobson, A. R. Crawford, D. Dewar, S. L. Pimlott and A. Sutherland, Bioorg. Med. Chem. Lett., 2009, 19, 4996-4998; (b) L. Stevenson, A. A. S. Tavares, A. Brunet, F. I. McGonagle, D. Dewar, S. L. Pimlott and A. Sutherland, Bioorg. Med. Chem. Lett., 2010, 20, 954-957; (c) S. L. Pimlott and A. Sutherland, Chem. Soc. Rev., 2011, 40, 149-162; (d) A. A. Cant, R. Bhalla, S. L. Pimlott and A. Sutherland, Chem. Commun., 2012, 48, 3993-3995.

9 F. Maya and J. M. Tour, Tetrahedron, 2004, 60, 81-91.

10 G. Adam, A. Alanine, E. Goetschi, V. J. Mutel and T. J. Woltering, World Patent WO01/29011, 2001.

11 D. Catarzi, V. Colotta, F. Varano, F. R. Calabri, G. Filacchioni, A. Galli, C. Costagli and V. Carla, J. Med. Chem., 2004, 47, 262272.
12 A. I. R. N. A. Barros and A. M. S. Silva, Magn. Reson. Chem., 2006, 44, 1122-1127.

13 J. Liu, J. Chen, J. Zhao, Y. Zhao, L. Li and H. Zhang, Synthesis, 2003, 2661-2666.

14 A. Pendri, S. Gerritz, D. S. Dodd and C. Sun, US Pat. 20050080087, 2005.

15 A. Klapars and S. L. Buchwald, J. Am. Chem. Soc., 2002, 124, 14844-14845.

16 A procedure was adapted from the following: http:// www.millipore.com/catalogue/item/hts146m. See $\mathrm{ESI}_{\dagger} \dagger$ for full details.

17 A. E. Kingston, P. L. Ornstein, R. A. Wright, B. G. Johnson, N. G. Mayne, J. P. Burnett, R. Belagaje, S. Wu and D. D. Schoepp, Neuropharmacology, 1998, 37, 1-12.

18 Previously, using rat mGluR2 transfected cell membrane and $1 S, 3 R$-ACPD as the agonist gave an $\mathrm{IC}_{50}$ of $110 \mathrm{nM}$ for Ro 645229 35: S. Kolczewski, G. Adam, H. Stadler, V. Mutel, J. Wichmann and T. Woltering, Bioorg. Med. Chem. Lett., 1999, 9, 2173-2176.

19 Physiochemical evaluation of compounds 3 and 6 was performed before biological testing. As the compounds did not show properties suitable for a neurological imaging agent, they were tested only twice.

20 A. A. S. Tavares, J. Lewsey, D. Dewar and S. L. Pimlott, Nucl. Med. Biol., 2012, 39, 127-135. 